\title{
Working Memory Training in Children with Neurodevelopmental Disorders
}

\author{
Sammy Roording-Ragetlie1, Helen Klip1, Jan Buitelaar',2,3, Dorine Slaats-Willemse ${ }^{1,4}$ \\ ${ }^{1}$ Karakter Child and Adolescent Psychiatry, Nijmegen, The Netherlands \\ ${ }^{2}$ Department of Cognitive Neuroscience, Radboud University Medical Centre, Donders Institute for Brain, \\ Cognition and Behaviour, Nijmegen, The Netherlands \\ ${ }^{3}$ Centre for Cognitive Neuroimaging, Donders Institute for Brain, Cognition and Behaviour, Radboud University, \\ Nijmegen, The Netherlands \\ ${ }^{4}$ Department of Psychiatry, Radboud University Medical Centre, Donders Institute for Brain, Cognition and \\ Behaviour, Nijmegen, The Netherlands \\ Email: s.roording@karakter.com
}

Received 18 January 2016; accepted 18 March 2016; published 21 March 2016

Copyright (C) 2016 by authors and Scientific Research Publishing Inc.

This work is licensed under the Creative Commons Attribution International License (CC BY).

http://creativecommons.org/licenses/by/4.0/

c) (i) Open Access

\begin{abstract}
In a naturalistic open label non-randomized controlled intervention study, Cogmed $(\subset$ working memory (WM) training effects were compared between different groups of children ( $n=99 ; 65$ boys, 34 girls), aged between 7 and 17 years with neurodevelopmental problems, i.e. ADHD ( $\mathrm{n}=$ $45)$, learning disorders $(L D, n=34)$ or learning problems $(n=20)$. Training efficacy after 25 sessions was measured by WM capacity improvement, ADHD DSM-IV rating scale and the BRIEF. It was hypothesized that training effects may lie on a continuum with those of the LD group at the lower end and those of the learning problems group at the upper end. Results partly confirmed the hypothesis in that all groups improved significantly with ADHD-children or children with learning problems showing the best results.
\end{abstract}

\section{Keywords}

Working Memory, Working Memory Training, ADHD, Learning Disorders, Learning Problems

\section{Introduction}

Today's changing society (bigger, stronger, faster) including rapid developments in information technology places a high burden on the immature brains of children. Typically developing children usually perform well in a more stressful daily life, however children vulnerable to developing Attention-Deficit Hyperactivity Disorder 
(ADHD) or learning disabilities may struggle to perform well in these conditions. The concept of working memory (WM) needs to be explored thoroughly in order to understand the difficulties children may encounter in environments with increased demands.

WM allows individuals to store, manipulate and retrieve task-relevant information in the presence of irrelevant distraction (Baddeley, 1992; Unsworth \& Engle, 2007). These cognitive capacities are of great importance in acquiring knowledge and new skills in daily life or at school. Substantial problems arise when WM deficits occur, requiring appropriate remedial support (Gathercole \& Alloway, 2006; Klingberg, 2010; Kenworthy, Yerys, Anthony, \& Wallace, 2008). Poor WM capacities are viewed as serious risk factors for learning disabilities and academic failure (Gathercole \& Pickering, 2000; Rogers, Hwang, Toplak, Weiss, \& Tannock, 2011), as well as maladjusted (classroom) behaviour and may play an important role in the development of neurodevelopmental disorders, such as ADHD and learning disabilities (Aronen, Vuontela, Steenari, Salmi, \& Carlson, 2005; Denckla, 1996).

According to Barkley's model, children with ADHD often suffer from deficits in executive functions, such as attentional control, inhibition and WM (Barkley, 1997). In this model WM deficits are seen in terms of downstream primary inhibitory impairments. WM deficits may also serve as potential core components of ADHD responsible for inhibition deficits (Rapport, Chung, Shore, \& Isaacs, 2001). Several meta-analytic reviews have stated that WM problems may be a key deficit or at least one of the core deficits in ADHD (Kasper, Matt Alderson, \& Hudec, 2012; Martinussen, Hayden, Hogg-Johnson, \& Tannock, 2005; Martinussen \& Tannock, 2006; Willcutt, Doyle, Nigg, Faraone, \& Pennington, 2005).

In respect of academic achievements, WM is seen as a strong predictor of reading abilities (Swanson \& Beebe-Frankenberger, 2004) and mathematical skills over time (Gathercole, Tiffany, Briscoe, Thorn, \& The ALSPAC Team, 2005; Mazzocco \& Kover, 2007; Toll, Van der Ven, Kroesbergen, \& Van Luit, 2011), even when controlling for IQ (Alloway \& Alloway, 2010; Cain, Oakhill, \& Bryant, 2004). Findings from metaanalyses indicate that children with reading disabilities as well as children with mathematical disabilities experience problems particularly with the verbal domain of WM (Swanson, Zheng, \& Jerman, 2009; Friso-van den Bos, van der Ven, Kroesbergen, \& van Luit, 2013). Children with severe disabilities in mathematics have also been found to have deficits in spatial WM (Passolunghi \& Mammarella, 2012).

It is apparent that WM problems seem to be relevant in both children with ADHD as in children with learning disabilities. Poor classroom behaviour and weak academic performance based on WM problems apply to both groups (Novik et al., 2006). From a neurobiological point of view, the shared WM deficits in children with ADHD and learning disabilities are not surprising. It is known that the dorsolateral prefrontal circuit function is associated with manipulating information in WM (Barbey, Koenings, \& Grafman, 2013) and that children with neurodevelopmental disorders, such as ADHD or learning disabilities, show abnormalities in the prefrontal cortex (Arnsten \& Rubia, 2012; Lazar \& Frank, 1998). Therefore, problems involving frontal systems or executive functions are not exclusive to ADHD: these are also prevalent in children with learning disabilities. Furthermore, it has been suggested that ADHD and learning disabilities could be viewed as co-occurring disorders sharing neurocognitive deficits based on shared genetic risk factors (Sexton, Gelhorn, Bell, \& Classi, 2012).

ADHD and learning disabilities therefore seem to have more in common than might be expected at first glance from a neuropsychological point of view. However, these neurodevelopmental problems are quite diverse in terms of diagnostic criteria. ADHD is defined by a pervasive pattern of symptoms of hyperactivity, impulsivity and/or inattention that is associated with impaired functioning (American Psychiatric Association, 2000). The term learning disabilities on the other hand refers to a heterogeneous group of disorders and problems that can be divided roughly into two groups: specific learning disorders (LD), and general learning problems. LD, like dyslexia or dyscalculia, refer to specific problems in a single domain of learning capacities or academic achievements. For instance, dyslexia is characterized by a specific and significant impairment in the development of reading skills (problems with accurate or fluent word recognition, poor decoding, poor spelling), while dyscalculia is characterized by a specific impairment in the acquisition of mathematical skills (problems with processing of numerical information, learning arithmetic facts, performing accurate and fluent calculations). Low IQ, visual or auditory acuity, mental or neurological disorders, psychosocial adversity, a lack of language proficiency or education, or inadequate educational instruction may not interfere with this specific impairment (American Psychiatric Association, 2013). LD occur in about 3\% to 6\% of all school aged children (SchulteKorne, 2010; Shalev, 2000) with prevalence rates similar to ADHD (Polanczyk, de Lima, Horta, Biederman, \& Rohde, 2007). 
The group of children with general learning problems is a quite difficult group to differentiate, but has significant clinical relevance. The term general learning problems refers to non-specific and possibly co-occurring disabilities in the following areas: 1) receptive language; 2) expressive language; 3) basic reading skills; 4) reading comprehension; 5) written expression; 6) mathematical calculation and reasoning; and 7) attention (Lyon, 1996). The group of learning problems is a heterogenic group characterized by a broad range of symptoms covering diverse academic achievement problems. Although symptoms may (at some stage) not meet DSM criteria for ADHD or LD, they may be associated with sub-threshold psychiatric problems. Children with learning problems may be “overlooked” struggling students, meeting minimal academic standards, often caused by processing strength and weaknesses that adversely affect school achievement. An expert panel consensus about specific LD observed the difficulty in distinguishing between children with LD and low achievers. This panel underlined the need to provide early preventive interventions based on specific (neuro-)cognitive strengths and weaknesses (Hale et al., 2010).

Without proper preventive treatment, neurocognitive problems and learning problems may develop into serious psychiatric problems and school drop-out. Learning problems are also associated with secondary psychosocial characteristics such as the lack of self-esteem (McNamara, Vervaeke, \& Willoughby, 2008). Children with ADHD, LD or learning difficulties need effective treatment in order to avoid gaps in their development and prevent mental health problems. First-line treatment for moderate to severe ADHD constitutes psycho-stimulants combined with parental training and/or behavioral therapy. On the other hand psychological treatments should be offered as first-line treatment for preschool and older children with mild and moderate ADHD (Trimbos-Instituut, 2005; Atkinson \& Hollis, 2010). Pharmacological treatments decrease ADHD symptoms in most children with ADHD (Ostberg \& Rydall, 2012). Nevertheless, alongside the concerns about potential sideeffects, a considerable percentage still remains with behavioral or cognitive problems at a two year follow-up, (MTA Cooperative Group, 2004; Swanson \& Volkow, 2009; Van der Loo-Neus, Rommelse, \& Buitelaar, 2011). Other interventions, such as neuro-feedback, diets and cognitive training need further research to confirm potential positive effects (Sonuga-Barke et al., 2013). Research has also shown that WM impairments in children with ADHD can be positively influenced by a combination of incentives and stimulant medication (Strand et al., 2012). For LD, intensive evidence-based remedial interventions, such as the Lindamood program for children with dyslexia or the Number Race game for children with dyscalculia, may improve learning-related performance, however these interventions alone may not be sufficient (Alexander \& Slinger-Constant, 2004; Butterworth, 2010). Furthermore, in learning problems such as decoding difficulties or reading comprehension problems, early intervention methods do not directly result in improvements in reading skills (see for a review Snowling \& Hulme, 2012).

While evidence has been mounting that WM impairments might be one of the core deficits in ADHD, LD and learning problems, research has also started to establish that WM capacity may be plastic and trainable (McNab et al., 2009). In terms of ADHD, a multicenter randomised controlled double-blind study has demonstrated improvements in a non-trained visuo-spatial WM task and on other neurocognitive functions as well as on parent ratings of inattention and hyperactivity-impulsivity up to 3 months after training (Klingberg, Forssberg, \& Westerberg, 2002; Klingberg et al., 2005). Other randomised controlled trials have shown that systematic WM training in children with ADHD resulted in positive long-term near transfer effects on visual WM capacity (Hovik, Saunes, Aarlien, \& Egeland, 2013) and in positive long-term far-transfer effects on ADHD deficits (Bigorra, Garolera, Guijarro, \& Hervas, 2015). Furthermore, a review on the efficacy of Cogmed WM training, has shown this system to be a potentially efficacious treatment for older children with ADHD (Chacko et al., 2013).

Two meta-analyses on non-pharmacological interventions for ADHD have been more critical and suggest that better evidence for the efficacy of cognitive training (attention training and WM training) is required before these interventions may be designated as effective interventions for ADHD (Cortese et al., 2015; Hodgson, Hutchinson, \& Denson, 2012; Sonuga-Barke et al., 2013). A meta-analysis on several cognitive training programs in children with ADHD showed moderate improvements in STM performance in studies using training STM alone (such as Cogmed WM training) - however distal transfer effects were negligible (Rapport, Orban, Kofler, \& Friedman, 2013). Additionally, two other reviews highlighted areas of concern in terms of the WM training effects in diverse patient groups, as well as with the different types of WM training methods. Inconsistent findings within and between studies has created doubt about the long-term effects and the generalization of the trained task effects (Melby-Lervag \& Hulme, 2012; Shipstead, Redick, \& Engle, 2012). Conclusions from these reviews have been criticized by others who have argued that WM capacity, attention and academic abili- 
ties do improve after Cogmed WM training (Shinaver, Entwistle, \& Söderqvist, 2014).

Furthermore, it has been shown that in typically developing children WM training enhances reading performance, e.g. speed and comprehension (Loosli, Buschkuehl, Perrig, \& Jaeggi, 2012). With respect to learning problems, WM training-induced improvements were found on non-trained visuo-spatial and verbal storage and manipulation tasks. Furthermore, a distal transfer effect was found in that (not trained) academic achievements improved after the intervention: significant gains with respect to mathematical ability were reported up to 6 months after training (Holmes, Gathercole, \& Dunning, 2009). A randomized controlled trial on the efficacy of WM training on reading skills in children with special needs reported improved performance on reading comprehension, related to an increased WM capacity (Dahlin, 2011). A randomised controlled trial in adolescents with severe LD and comorbid ADHD showed effects of Cogmed WM training on two of the three trained WM tasks (Gray et al., 2012). However, no transfer effects were found on non-trained cognitive tasks, parent- or teacher-rated ADHD symptoms, or measures of academic achievement. Supplemental analysis showed significant effects of time (regardless of training program) on cognitive attention, reading and mathematics as well as on parent-reported ADHD symptoms. In conclusion, studies on the efficacy of WM training in children with ADHD, LD or learning problems are inconclusive. Further exploration of direct and distal transfer training effects is therefore needed.

Studies to-date on the efficacy of Cogmed have examined training effects in patients from one diagnostic category and compared those with normal controls or placebo conditions (e.g., ADHD: Chacko et al., 2013; learning problems: Holmes et al., 2009). The present study adds to the literature by comparing training effects between different diagnostic groups, i.e. ADHD, LD and learning problems. Studying these different subgroups with neurodevelopmental problems is of great interest, since they represent a large proportion of the clinical population. In addition, comparing different diagnostic groups that differ in the extent of WM deficits may shed light on the range of treatment effects that can be achieved.

The aim of this study is to examine differences in efficacy of WM training in three groups of children with neurodevelopmental problems, i.e. ADHD, LD and learning problems. Apart from aetiology, differences in WM and learning problems between these three groups can be found in terms of the severity of neurocognitive impairments (Willcutt et al., 2010). Children with learning disabilities generally perform worse on WM tests compared to children with ADHD (Lazar \& Frank, 1998). It is known from the literature that children with general learning problems have mixed but relatively higher WM scores compared to children with LD (Jeffries \& Everatt, 2004). Therefore, the largest training effects are expected in the learning problems group characterized by milder, less pervasive cognitive or WM problems, compared to the other groups, due to the higher degree of sensitivity of these children to training.

\section{Methods}

\subsection{Subjects}

Subjects were recruited in fifteen independent private practices (Psychological Primary Health Care) in the Netherlands, selected by BeterBrein, the Dutch Cogmed $\odot$ licence holder at the time of the study. Subjects were asked by their therapist to participate in this study facilitated by the mental healthcare cooperation UVIT/VGZ. The children were attending private practices for the treatment of attention or memory problems or other learning difficulties that were interfering with their academic achievements. The Cogmed training was free of charge for the subjects.

The inclusion criteria for this study were children aged between 4 to 17 years of age, with a DSM-IV-TR classification of ADHD or LD (dyslexia, dyscalculia or learning disorder not otherwise specified), diagnosed (according to DSM-IV-TR criteria) by a registered clinical psychologist in an independent private practice. For those cases of dyslexia and dyscalculia, the diagnoses were based on the Dutch guidelines for these learning disorders (Masterplan dyslexia; http://masterplandyslexie.nl/nl/pages/masterplan). Children in the same age range with learning problems (but without a DSM-IV diagnosis) were also included. These children were experiencing academic achievement problems (lower grades than expected) and mixed neuropsychological impairments (memory- or attention problems in the classroom), as well as learning-related behavioural problems (Alloway \& Alloway, 2010). Learning problems were diagnosed according to an official Dutch system that monitors academic achievement at school supplemented by the clinical opinion of the clinical psychologist and reports by parents and teachers about the child's development. For these children treatment of their learning prob- 
lems had been recommended by a registered clinical psychologist in an independent private practice.

Subjects were excluded where there was 1 ) a medical illness requiring immediate treatment as this meant that participating in an intensive training would be too demanding; 2) a motor or perceptual disability preventing the subject from using the computer program; 3) no access to a personal computer with an internet connection at home or in school; 4) a lack of motivation (e.g. willingness on the part of the parents to participate, but not on the part of the child); or 5) a co-morbid (psychiatric) diagnosis.

A total of 122 children were recruited. Seventeen children were excluded due to a co-morbid diagnosis: Rett's syndrome $(n=3)$, Expressive Language Disorder $(n=2)$, Autism Spectrum Disorder $(n=1)$, Developmental Coordination Disorder $(\mathrm{n}=1)$, and Internalizing problems such as anxiety, depressive and psychosomatic symptoms $(n=9)$. One child was excluded as the treatment was not in line with the diagnosis. This particular child was diagnosed with LD and was taking ADHD related medication. Six children were excluded due to missing data (outcome measure questionnaires not completed by the parents before and after training). Data from 99 children were analysed. Seventy-nine subjects were diagnosed with a DSM-IV-TR classification of ADHD or LD. Forty-five of these children were diagnosed with ADHD (inattentive subtype $(n=25)$, combined subtype ( $n=13$ ), not otherwise specified (NOS $n=7$ ). Thirty-four children were diagnosed with LD (dyslexia $(n=25)$, dyscalculia $(n=3)$, not otherwise specified (NOS $n=6)$ ). Twenty subjects did not meet the criteria for a DSM-IV-TR classification. These children were experiencing learning problems, such as mild symptoms of inattention and/or academic achievement or learning related behaviour problems (see Figure 1).

Seven children were taking psycho-stimulants (Concerta $(n=1)$, Ritalin $(n=5)$, Medikinet $(n=1)$ ). Psychostimulant use was not an exclusion criterion, since exclusion of the medicated children might preclude generalisation of the results. The dosage of the medication remained stable during the five-week training period. Criterion for inclusion was room for improvement, defined as "still having significant DSM-IV-TR related ADHD problems interfering with daily life". This was the case in these seven children (all diagnosed with ADHD).

\subsection{Outcome Measures}

Behavioural outcome was measured by the total score of inattention and ADHD hyperactive/impulsive symptoms to the Dutch version of the ADHD rating scale (ADHD Vragen Lijst, AVL; Scholte \& Van der Ploeg, 2005). In this rating scale eighteen ADHD related items, based on the DSM-IV-TR, are measured on a five point

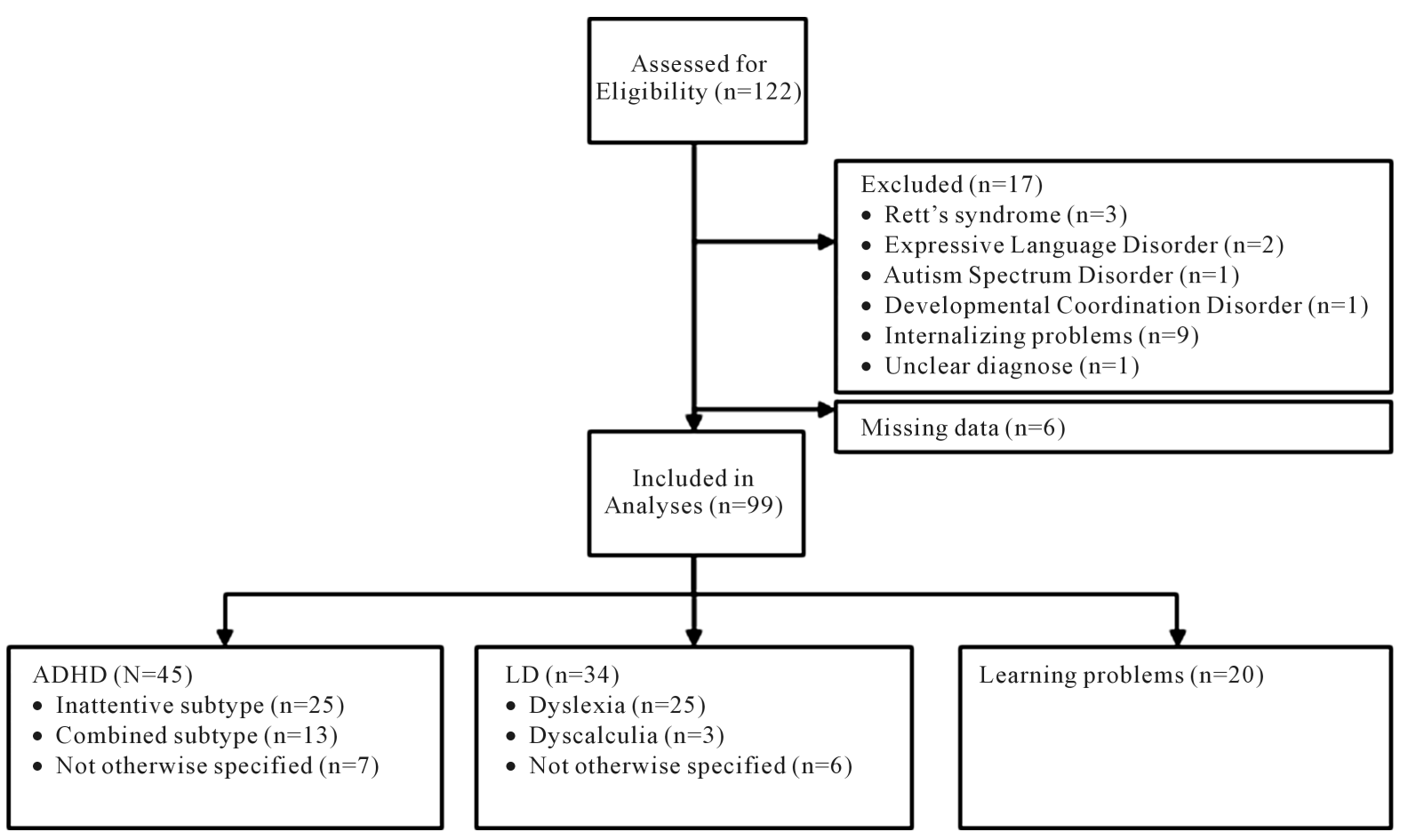

Figure 1. Flow diagram of included children. 
scale. Behavioural outcome was also measured by the total score and WM subscale of executive function problems (experienced daily) from the Dutch version of the Behaviour Rating Inventory of Executive Function checklist (BRIEF; Gioia, Isquith, Guy, \& Kenworthy, 2000; Smidts \& Huizinga, 2009). The Dutch version of the BRIEF has a high reliability (total score BRIEF: Cronbach's $\alpha=0.93$; test-retest reliability 0.86) and a high convergent validity when compared with the Child Behavior Checklist (CBCL: total score BRIEF and total score CBCL $r=0.75$ ), (Verhulst, Van der Ende, \& Koot, 1996). The ADHD rating scale and the BRIEF were completed by parents before, and 4 - 6 weeks after training.

WM capacity improvement was measured by the Cogmed computer program on two Cogmed $\odot$ components (visual data link and input module recall) on training days two and three less the mean score on the two highest scores on these components.

\subsection{Intervention}

Cogmed WM training consists of 13 verbal and visual short-term memory and WM tasks, implemented using a computer program (Cogmed@, Stockholm, Sweden). A child will complete eight different task on each training session. An example of a verbal WM task is Decoder. In this particular task, some letters will be said aloud, while three letters are shown at the same time with the corresponding letter highlighted. The child needs to remember the letters that he/she hears and select the letters by clicking on them without becoming distracted by the other non-corresponding letters shown on the display. An example of a verbal WM task is Rotating data link. In this particular task a number of lamps will be highlighted in a successive order. The child needs to remember the order. Before the child gives an answer, the entire panel will be turned through 90 degrees. When the program says "go", the child clicks on the circles in the order in which the lamps were highlighted, however they need to remember that the panel has turned 90 degrees. The JM version for toddlers only includes visual short-term and WM tasks. The RM version for children aged between 7 to 17 years, includes verbal and visual short-term and WM tasks (JM; $n=4, \mathrm{RM} ; \mathrm{n}=95)$. The children in the JM condition were all 7 years of age, diagnosed with ADHD and free of medication.

The program was provided on a compact disc and used by the child on a personal computer at home, supervised by a parent. This supervision included additional task instructions, encouraging the child to continue with the tasks when training becomes more difficult, taking a break when fatigued, or avoiding external distractors. The children undertook the same amount of sessions ( 25 in total) and exercises (8 different exercises each training session and 15 rehearsals per exercise). Total training time depended on the time needed to finish the complete training including the breaks taken between the exercises, and the difficulty level they reached, as this led to more items to remember and therefore a (little) longer time required to respond. Responses were made by clicking on displays using the computer mouse. The difficulty level was automatically adjusted, on a trial-bytrial basis, to match the WM span of the child on each task. Children were assigned a unique ID code to ensure anonymity. Task performance was uploaded in a log file. Adherence to training was monitored through weekly telephone calls by a personal coach, who provided feedback about individual performances. The personal coach followed a strict protocol as part of the training program. Motivational features were included as part of the program to enhance adherence to training. During the training sessions the child received positive verbal feedback from the computer. Furthermore high scores were displayed after each task; there was also an "energy" counter shown which could be used on a fun racing game after each training day was completed. The racing game was only included as a reward and did not load on WM. Children had a free choice whether to play the game. After each week of training the child received a small reward (e.g. doing something fun with dad, choosing dinner).

\subsection{Procedures}

Parents of children meeting the criteria were informed verbally about the study. Children and their parents who were willing to participate in the study were sent more detailed written information, which specified the inclusion criteria in terms of diagnostic classification, age and the need for a computer with internet access. All inclusion and exclusion criteria were checked by a psychologist at the screening visit with the child and one of the parents. The parents of the included children were asked to complete the baseline questionnaires (AVL, BRIEF). Detailed information about the computer program was provided and the parents were asked to sign an agreement detailing treatment goals and to the requirement to complete at least 25 days of training. Appointments for weekly supportive coach calls were arranged. These coach calls were used to discuss technical difficulties and 
information about training progress. The post-intervention visit took place 5 to 6 weeks after the baseline visit, at which the same questionnaires were completed by the parent. A social validation questionnaire was sent a couple of days after the post-intervention visit to measure client satisfaction with regard to the training program, procedures and the psychologist's coaching.

\subsection{Statistical Analysis}

Descriptive statistics are reported for each variable of interest for the three groups (ADHD, LD and learning problems). Categorical variables are presented as counts and percentages; continuous variables include the mean and standard deviation. First univariate analyses were carried out. An one-way ANOVA was conducted to determine if age was different for the three groups (ADHD, LD and learning problems). A chi-square test was used to examine whether there was an association between gender, use of medication, the Cogmed version and the group (ADHD, LD and learning problems). An independent-samples t-test was run to determine if there were differences in the AVL, BRIEF and Cogmed WM capacity between gender, between use of medication and between Cogmed version.

Secondly, we looked at the percentages of children in the (sub)clinical range at pre-treatment in the three different groups for the AVL (normal range (0-11), (sub)clinical range ( $\geq 12$ ) (Scholte \& van der Ploeg, 2005) and the BRIEF (normal range $(0$ - 49), (sub)clinical range ( $\geq 50)$ ) (Smidts \& Huizinga, 2009). For WM start index, mean \pm standard deviation are presented.

A $2 \times 3$ repeated measures ANOVA was run to determine the effect of AVL, BRIEF and Cogmed WM capacity between pre-treatment and post-treatment for the three groups (ADHD, LD and learning problems). Post hoc Bonferroni $t$ tests were used to detect differences between the individual three groups where the main for group was statistically significant. Since univariate analyses showed no effect of age, gender or use of medication for any of the outcome variables and for the three groups (ADHD, LD and learning problems) these covariates were not included in the further analyses. Effect sizes are reported using the Partial eta-squared. Effect sizes of 0.8 are considered large and effect sizes between 0.5 and 0.8 are moderate. Data analysis was performed using the Statistical Package for the Social Sciences (SPSS for Windows, version 21.0).

\section{Results}

The majority of subjects were boys in all groups. Mean age in all groups was 10.3 years (range: 7 to 17). Most of the children were free of medication. In $25 \%$ of the total sample, information about medication use was unknown. However, in most cases this involved children in the LD or learning problems groups. In these groups, it is not plausible that the children used ADHD related medication due to the medication policy in primary health care, e.g. in the Netherlands, children with LD or learning problems are not diagnosed or treated by doctors but by psychologists and these professionals are not allowed to prescribe medication. In seven children with ADHD (7\% of the total sample) information about medication use was missing. See Table 1 for descriptive details of the subjects and medication use.

As shown in Table 2, at baseline the larger proportion of children with LD fell into the normal AVL-I range (standardized residual: 2.4), whereas children with ADHD and learning problems mostly fell into the clinical range. The baseline measure in terms of hyperactivity/impulsivity symptoms were alike for the three groups with the majority of the children falling into the normal range. Furthermore, Brief total score and WM start index did not differ at baseline between groups. The WM start index was at a normal range, compared to other clinical groups of children treated with Cogmed WM training (mean 73, aged 7 - 17; Cogmed manual).

There was a significant main effect with small to moderate effect sizes for three outcome measures (AVL-I $F(1,93)=122.4, p<0.0001$, partial $\eta^{2}=0.57$; AVL-H/I $F(1,93)=45.9, p<0.0001$, partial $\eta^{2}=0.33$; BRIEF Total $F(1,95)=35.3, p<0.0001$, partial $\eta^{2}=0.27$; and a high effect size for WM index $F(1,96)=901.9, p<$ 0.0001 , partial $\eta^{2}=0.90$ ), suggesting that all groups (ADHD, LD and learning problems) profit from training in terms of their inattention symptoms, hyperactivity/impulsivity symptoms, overall executive function problems and WM capacity (Figure 2 \& Table 3).

There was a statistically significant interaction between treatment and time for hyperactivity/impulsivity symptoms $\left(\mathrm{AVL}-\mathrm{H} / \mathrm{I}, F(2,93)=3.30, p=0.041\right.$, partial $\left.\eta^{2}=0.07\right)$. Furthermore, the results showed a statistically significant interaction effect with small effect sizes for the BRIEF (Total $F(2,95)=5.32, p=0.006$, partial 
Table 1. Subject characteristics $(n=99)$.

\begin{tabular}{|c|c|c|c|c|c|c|c|}
\hline & \multicolumn{2}{|c|}{$\begin{array}{l}\text { ADHD } \\
\mathrm{n}=45\end{array}$} & \multicolumn{2}{|c|}{$\begin{array}{l}\text { Learning disorder } \\
\qquad \mathrm{n}=34\end{array}$} & \multicolumn{2}{|c|}{$\begin{array}{l}\text { Learning problems } \\
\qquad \mathrm{n}=20\end{array}$} & \multirow{2}{*}{ p-value ${ }^{a}$} \\
\hline & $\mathrm{n}$ & $\%$ & $\mathrm{n}$ & $\%$ & $\mathrm{n}$ & $\%$ & \\
\hline \multicolumn{8}{|l|}{ Gender } \\
\hline Boy & 32 & $71 \%$ & 18 & $53 \%$ & 15 & $75 \%$ & \multirow{2}{*}{0.149} \\
\hline Girl & 13 & $29 \%$ & 16 & $47 \%$ & 5 & $25 \%$ & \\
\hline \multicolumn{8}{|l|}{ Medication } \\
\hline No & 31 & $69 \%$ & 18 & $53 \%$ & 18 & $90 \%$ & \multirow{3}{*}{0.292} \\
\hline Yes & 7 & $16 \%$ & 0 & $0 \%$ & 0 & $0 \%$ & \\
\hline Unknown ${ }^{*}$ & 7 & $16 \%$ & 16 & $47 \%$ & 2 & $10 \%$ & \\
\hline \multicolumn{8}{|l|}{ Version cogmed } \\
\hline $\mathrm{J} / \mathrm{M}$ & 4 & $9 \%$ & 0 & $0 \%$ & 0 & $0 \%$ & \multirow{2}{*}{0.082} \\
\hline \multirow[t]{2}{*}{$\mathrm{R} / \mathrm{M}$} & 41 & $91 \%$ & 34 & $100 \%$ & 20 & $100 \%$ & \\
\hline & \multicolumn{2}{|c|}{ Mean $( \pm$ SD) } & \multicolumn{2}{|c|}{ Mean $( \pm$ SD) } & \multicolumn{2}{|c|}{ Mean $( \pm$ SD) } & p-value \\
\hline Age & \multicolumn{2}{|c|}{$10.3( \pm 2.5)$} & \multicolumn{2}{|c|}{$10.3( \pm 2.4)$} & \multicolumn{2}{|c|}{$10.3( \pm 2.5)$} & 0.998 \\
\hline
\end{tabular}

Note: $\mathrm{ADHD}=$ Attention Deficit Hyperactivity Disorder, $\mathrm{SD}=$ Standard Deviation. ${ }^{*}$ Unlikely that medication was subscribed in de LD and learning problems group, because of medication policy in primary health care in The Netherlands; ${ }^{\mathrm{a}}$ Chi-square test; ${ }^{\mathrm{b}}$ Anova.

Table 2. Baseline measurements $(n=99)$.

\begin{tabular}{|c|c|c|c|c|c|c|c|}
\hline & \multicolumn{2}{|c|}{$\begin{array}{l}\text { ADHD } \\
\mathrm{n}=45\end{array}$} & \multicolumn{2}{|c|}{$\begin{array}{l}\text { Learning disorder } \\
\qquad \mathrm{n}=34\end{array}$} & \multicolumn{2}{|c|}{$\begin{array}{l}\text { Learning problems } \\
\qquad \mathrm{n}=20\end{array}$} & \multirow{2}{*}{ p-value ${ }^{c}$} \\
\hline & $\mathrm{n}$ & $\%$ & $\mathrm{n}$ & $\%$ & $\mathrm{n}$ & $\%$ & \\
\hline \multicolumn{8}{|l|}{ AVL-I ${ }^{\mathrm{a}}$} \\
\hline Normal range & 7 & $16 \%$ & 17 & $50 \%$ & 4 & $20 \%$ & \multirow{3}{*}{$0.002^{\mathrm{e}}$} \\
\hline (Sub)clinical range & 37 & $82 \%$ & 16 & $47 \%$ & 15 & $75 \%$ & \\
\hline Missing & 1 & $2 \%$ & 1 & $3 \%$ & 1 & $5 \%$ & \\
\hline \multicolumn{8}{|l|}{$\mathrm{AVL}-\mathrm{H} / \mathrm{I}^{\mathrm{a}}$} \\
\hline Normal range & 29 & $64 \%$ & 27 & $79 \%$ & 14 & $70 \%$ & \multirow{3}{*}{0.298} \\
\hline (Sub)clinical range & 15 & $33 \%$ & 6 & $18 \%$ & 5 & $25 \%$ & \\
\hline Missing & 1 & $2 \%$ & 1 & $3 \%$ & 1 & $5 \%$ & \\
\hline \multicolumn{8}{|l|}{ BRIEF total $^{\mathrm{b}}$} \\
\hline Normal range & 11 & $24 \%$ & 17 & $50 \%$ & 5 & $25 \%$ & \multirow{3}{*}{0.145} \\
\hline (Sub)clinical range & 33 & $73 \%$ & 17 & $50 \%$ & 15 & $75 \%$ & \\
\hline \multirow[t]{2}{*}{ Missing } & 1 & $2 \%$ & 1 & $3 \%$ & 1 & $5 \%$ & \\
\hline & \multicolumn{2}{|c|}{ Mean $( \pm$ SD) } & \multicolumn{2}{|c|}{ Mean $( \pm \mathrm{SD})$} & \multicolumn{2}{|c|}{ Mean $( \pm$ SD) } & p-value \\
\hline WM start index & \multicolumn{2}{|c|}{78.4 (12.9) } & \multicolumn{2}{|c|}{75.8 (10.5) } & \multicolumn{2}{|c|}{$74.9(15.0)$} & 0.501 \\
\hline
\end{tabular}

${ }^{\mathrm{a}}$ Normal range $(0-11)$, (sub)clinical range $(\geq 12)$ for AVL were based on the manual (Scholte \& van der Ploeg, 2005); ${ }^{b}$ Normal range $(0$ - 49), (sub)clinical range $(\geq 50)$ for BRIEF were based on the manual (Smidts \& Huizinga, 2009); 'Chi-square test. Missing category was not included in the Chi-square test; ${ }^{\mathrm{d}} \mathrm{ANOVA}$; ${ }^{\mathrm{A}} \mathrm{A}$ significantly larger group of children with LD fall in the normal AVL-I range (std. residual: 2.4 ); Note: ADHD = Attention Deficit Hyperactivity Disorder, SD = Standard Deviation, AVL-I = inattention scale AVL, AVL-H/I = Hyperactivity/Impulsivity scale AVL, BRIEF Total $=$ Total score BRIEF, WM = Working Memory. 
Table 3. Main effects and Interaction effects on the AVL, BRIEF and Cogmed WM capacity between pre-treatment and post-treatment for the three groups (ADHD, LD and learning problems).

\begin{tabular}{|c|c|c|c|c|c|c|c|c|}
\hline & \multicolumn{2}{|c|}{$\begin{array}{l}\text { ADHD } \\
\mathrm{n}=45\end{array}$} & \multicolumn{2}{|c|}{$\begin{array}{l}\text { Learning disorder } \\
\qquad \mathrm{n}=34\end{array}$} & \multicolumn{2}{|c|}{$\begin{array}{l}\text { Learning problems } \\
\qquad \mathrm{n}=20\end{array}$} & \multirow{2}{*}{ Main effect ${ }^{a}$} & \multirow{2}{*}{$\begin{array}{l}\text { Interaction } \\
\text { effect }^{\mathrm{a}}\end{array}$} \\
\hline & Before & After & Before & After & Before & After & & \\
\hline & Mean $( \pm$ SD) & Mean $( \pm \mathrm{SD})$ & Mean $( \pm$ SD) & Mean $( \pm \mathrm{SD})$ & Mean $( \pm$ SD) & Mean $( \pm \mathrm{SD})$ & $p / \eta^{2}$ & $p / \eta^{2}$ \\
\hline AVL-I & $17.1( \pm 6.0)$ & $11.2( \pm 5.4)$ & $12.5( \pm 6.4)$ & $8.2( \pm 4.4)$ & $15.7( \pm 5.8)$ & $9.7( \pm 5.3)$ & $\begin{array}{c}p<0.0001 \\
\eta^{2}=0.568\end{array}$ & $\begin{array}{l}p=0.282^{b} \\
\eta^{2}=0.027\end{array}$ \\
\hline AVL-H/I & $9.5( \pm 6.5)$ & $6.6( \pm 4.6)$ & $6.0( \pm 6.3)$ & $4.4( \pm 4.2)$ & $8.3( \pm 6.9)$ & $3.8( \pm 4.0)$ & $\begin{array}{c}p<0.0001 \\
\eta^{2}=0.331\end{array}$ & $\begin{array}{l}p=0.041^{c} \\
\eta^{2}=0.066\end{array}$ \\
\hline BRIEF total & $56.4( \pm 10.3)$ & $51.0( \pm 9.2)$ & $50.7( \pm 11.7)$ & $49.5( \pm 10.0)$ & $54.4( \pm 9.3)$ & $47.6( \pm 10.1)$ & $\begin{array}{c}p<0.0001 \\
\eta^{2}=0.271\end{array}$ & $\begin{array}{l}p=0.006 \\
\eta^{2}=0.101\end{array}$ \\
\hline WM index & $78.4( \pm 12.9)$ & $104.4( \pm 16.4)$ & $75.8( \pm 10.8)$ & $100.9( \pm 13.1)$ & $74.9( \pm 15.1)$ & $103.3( \pm 15.2)$ & $\begin{array}{c}p<0.0001 \\
\eta^{2}=0.904\end{array}$ & $\begin{array}{l}p=0.359 \\
\eta^{2}=0.21\end{array}$ \\
\hline
\end{tabular}

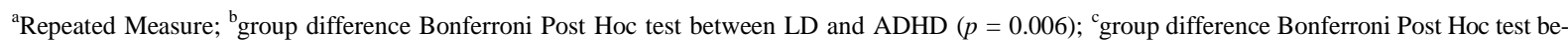
tween LD and ADHD ( $p=0.057)$; Note: ADHD = Attention Deficit Hyperactivity Disorder, SD = Standard Deviation, AVL-I = inattention scale AVL, AVL-H/I = Hyperactivity/Impulsivity scale AVL, BRIEF Total = Total score BRIEF, WM index = Working Memory index Cogmed.

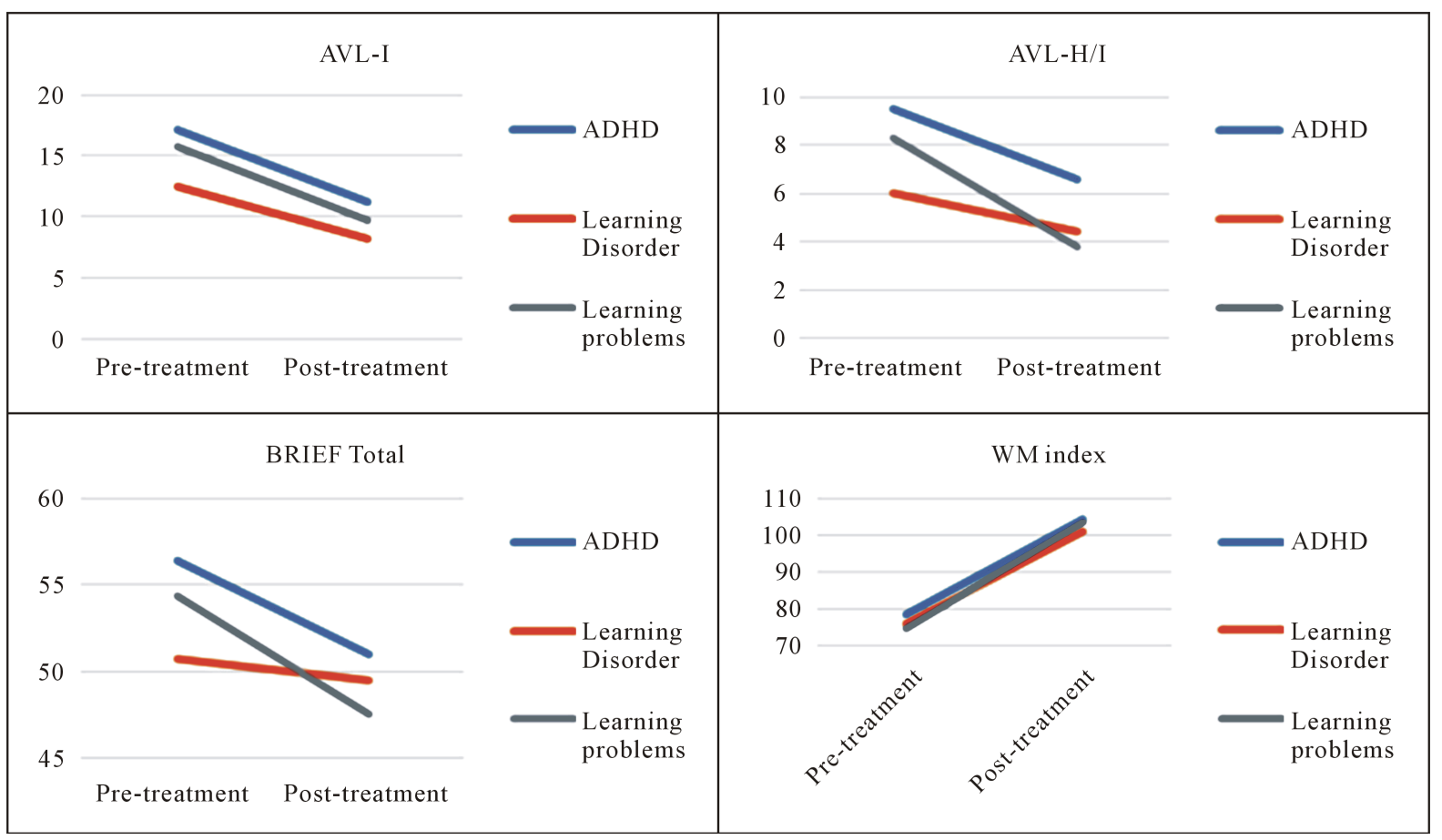

Figure 2. AVL, BRIEF and Cogmed WM capacity between pre-treatment and post-treatment for the three groups (ADHD, Learning disorder and learning problems).

$\left.\eta^{2}=0.10\right)$. This suggests that children with LD profit less from training regarding hyperactivity/impulsivity symptoms and overall executive function problems, compared to children with ADHD or LD. No interaction effects were found on inattention symptoms and Cogmed improvement index.

Post hoc Bonferroni analysis revealed that at post treatment AVL-I was statistically different between LD and ADHD $(p=0.0006)$ and the AVL-H/I was borderline statistically significantly between LD and ADHD $p=$ 0.057). 
We also re-ran the analyses excluding children using psychopharmaceuticals $(\mathrm{n}=7)$, the young children treated with the J/M-version of Cogmed WM training $(n=4)$ and children with dyslexia $(n=3)$. The significant main effects and interactions effects on all outcome measures stayed the same.

\section{Discussion}

This study examined the efficacy of Cogmed WM training in three groups of children with neurodevelopmental problems, i.e. ADHD, LD and learning problems. It was hypothesized that training effects may lie on a continuum with those of the LD group at the lower end and those of the learning problems group at the upper end, due to differences in the distribution of WM problems between groups and therefore differences in sensitivity to training.

The results partly confirmed our continuum hypothesis. A significant main effect with small to moderate effect sizes was found on inattention symptoms, hyperactivity/impulsivity symptoms, overall executive function problems and with a high effect size for WM capacity, suggesting that all groups (ADHD, LD and learning problems) benefit from training. Furthermore, significant interaction effects with small effect sizes revealed that children with LD profit less from training in respect of hyperactivity/impulsivity symptoms and overall executive function problems, compared to children with ADHD. All groups profit equally from training regarding behavioural attention and WM capacity.

An explanation for the differences in improvement between the LD group versus the ADHD group on overall executive functioning problems, could be that the LD group may need more time to establish behavioural and EF-related improvements in daily life. This delayed effect has also been found on academic skills in a study on Cogmed training effects using a comparable group (Holmes et al., 2009). Immediately after training, small non-significant effects were found on measures of academic skills, however six months after training mathematics performance appeared to be significantly improved (Holmes et al., 2009). It sounds reasonable that it takes some time to experience the benefits of cognitive training in daily life in activities requiring higher order cognitive functioning, such as WM and EF.

Perhaps another explanation could be that for the LD group the training is not primarily WM training but attention training. This is in line with the finding that $37 \%$ of the self-reports of Cogmed trained LD children showed enhanced attentional focus (Holmes et al., 2009). WM and controlled attention are closely related and improvement in WM capacity might mediate improvements in attention. WM and controlled attention rely on the same mechanisms of substained neural activity and top-down excitation, and the same multi-model frontoparietal network (Klingberg, 2010). In this way, connected neural systems might explain WM training-related generalization effects to controlled attention (Klingberg, 2010).

A final explanation for the differences in efficacy of WM training in LD may be that other cognitive factors play a more crucial role in LD, such as comprehension, listening and writing (Semrud-Clikeman, 2005), and phonological deficits in cases of dyslexia and a deficient number module in cases of dyscalculia (Landerl, Fussenegger, Moll, \& Willburger, 2009).

It could also be posited that the lack of differences in the LD group may be purely due to the measures chosen. The improvement in the inattention measure was only about 4 points and could have been purely due to chance. However, in this particular group the inattention symptoms were scored at a subclinical level before training (AVL inattention cut-off score stands at 12 points), reaching an average level after training. Therefore we believe that this still is a clinically relevant finding, since children with dyslexia often have attention problems and vice versa. Tannock and Brown (2000) reported that $12 \%-24 \%$ of the children diagnosed with dyslexia also had ADHD, and 15\% - 30\% of the children diagnosed with ADHD (without considering sub-types) were estimated to have comorbid dyslexia.

As mentioned earlier, children with LD seem to profit less from training compared to children with ADHD on hyperactivity/impulsivity problems. This is a rather remarkable finding since treatment effects on hyperactivity/ impulsivity problems in children with LD may not be expected in light of classification criteria and behavioural problems experienced daily (American Psychiatric Association, 2013; Lyon, 1996). When looked at more closely, children in our study with learning problems showed a considerably higher baseline measurement regarding hyperactivity/impulsivity problems (meaning more problems) compared to children with LD. Perhaps the fact that there was less room for improvement in the LD group may explain the difference found in terms of benefit between these groups. The learning problems group is a rather diffuse and heterogeneous group with 
non-specific and possibly co-occurring disabilities compared to the rather isolated problems in the LD group. It is therefore plausible that some children in the learning problems group experienced more hyperactivity/impulsivity problems than considered prior to the study. This could also explain why the LD group did not show an effect when the interaction was considered. Other research has shown that children with reading disabilities have lower WM span levels, yet as they age they show similar WM growth, compared to children without reading disabilities. In addition, inhibition difficulties, more so than WM difficulties, constrain growth in reading performance (Jerman, Reynolds, \& Swanson, 2012). Furthermore, these findings in the learning problems group could be caused by statistical phenomena, such as a reduced power and increased risk of Type II errors.

Our results suggest that Cogmed(C WM training could be an effective training program for children with neurodevelopmental problems with the best results for children with ADHD or learning problems. These findings add to the accumulating evidence that WM training may indeed reduce attention and memory problems, learning difficulties and academic achievement problems, and suggest plasticity of the brain in children with neurodevelopmental problems across a wide age range.

However, the results should be viewed in light of some limitations. A major limitation of this study is the absence of a randomized design and a control condition. Therefore, the positive results in this study were not controlled for unspecific factors, such as invested time and attention, therapist interaction, or brain maturation. However, clinical intervention studies are valuable because of their realistic character and better fit to daily life. The children participating in this study received active weekly Cogmed coaching, which might be (one of the) the most important component(s) in the training program. In previous randomized controlled trials on the efficacy of Cogmed, coaching was solely based on encouraging and motivating parents and children, and - in contrast to Cogmed in clinical practice_could not be based on individual training results as the coach was blinded to group assignment (due to the triple-blind design).

Another limitation could be that the only WM measurement used in this study was the WM capacity improvement index measured by the Cogmed (C computer program itself, which is not a pure clinical measure and is susceptible to practice effect. On the other hand, differences in practice level might be of interest, given we know that improvement index levels between individuals can be quite various. Therefore it might be of value that this study has demonstrated that some groups of clinical patients benefit more from training than others and therefore show more improvement on trained tasks than others. Furthermore, the fact that the parent reports were not anonymised, and (potentially more neutral) teacher ratings were not included may have created an expectancy bias resulting in more positively rated training effects (Caspi \& Bootzin, 2002; Sonuga-Barke et al., 2013). However, our results showed no observer bias effect for children with LD on BRIEF measures, as the (mild) behavioral problems still remained after training. Additionally, the results may be interpreted as parent-reported improved quality of life.

Meta-analyses have been sceptical about the efficacy of training programs such as Cogmed, however these reviews mostly represent children diagnosed with psychiatric disorders, e.g. moderate to severe ADHD, often in combination with other comorbid psychiatric disorders. An important point not stressed in these reviews is the potential influence of the severity of the neurodevelopmental problems. Our study focused on mild behavioural and learning disabilities. The majority (71\%) of the ADHD group was diagnosed with the inattentive subtype or "not otherwise specified" and none of the ADHD children had comorbid disorders. Although all subjects were diagnosed by a range of practitioners we consider this group as a mixed group of children without a full psychiatric disorder, even though this could possibly have led to a potential contribution to variability within the diagnosis of children within the sample, especially the heterogenic learning problems group. However, in our opinion this is an important and large group of children at risk of developing a psychiatric disorder/severe LD or leaving school early. Neurocognitive problems and learning disabilities may be precursors of psychiatric disorders. So, while evidence for WM training induced generalization effects in complex psychiatric populations is not convincing, our study shows that Cogmed WM training might be (more) useful for children with relatively mild or subthreshold psychiatric disorders or learning disabilities at risk for a severe psychiatric disorder. This might prevent the development of a full psychiatric disorder or severe academic achievement problems. Our findings show that this "at risk-group” of children profit from a relatively short, but intensive Cogmed training program. Therefore, low cost interventions such as Cogmed WM training could possibly prevent the development of severe neuropsychiatric disorders.

Another point to take into account is that medication use in this sample seems low. An explanation could be found in the way the Dutch mental health care system works. In the Netherlands, children with mild psychiatric 
disorders are diagnosed and treated in (private) psychological practices by psychologists (not doctors), and not in child psychiatric centers or hospitals. In line with the ADHD guidelines (Trimbos-Instituut, 2005; Atkinson \& Hollis, 2010) psychological treatments are offered as first-line treatment for children with mild ADHD. Comorbidity in this relatively mild ADHD group is less likely compared to children with full-blown ADHD that are treated in child psychiatric hospitals.

Further longitudinal research on WM training is needed in large groups of children with different levels of severity of neurodevelopmental disorders to examine the effect of severity, age, distal transfer and long-term effects (Klingberg, 2010; Chacko et al., 2013). The training program could be extended by training-related exercises at home in order to enhance transfer and generalisation effects. Incorporation of WM tasks in daily life could improve executive functioning and academic achievements.

Future research should use a randomized placebo-controlled design in a naturalistic setting, and blind ratings of subjective behavioural change in daily life. Studies could also include multiple ecologically valid measures of neurocognitive functioning to measure near and distal transfer effects when comparing groups of children with neurodevelopmental disorders. In doing so, it would be interesting to use the baseline WM capacity level, measured with an independent neuropsychological assessment, to include only those children with actual WM deficits in the training problem (as we are aware that WM deficits in the patient groups described are based on group results, which does not mean that some individuals do not experience WM problems at all). Furthermore, more research focussing on the underlying (secondary) mechanism of WM training, e.g. the role of systematic coaching during training is needed. The above is in line with three recent meta-analytic reviews reporting that WM training programs produce short-term, specific training effects that do not generalize (Melby-Lervag \& Hulme, 2012; Shipstead et al., 2012; Sonuga-Barke et al., 2013). Isolated WM training might not be adequate to improve executive functioning in daily life (Diamond \& Lee, 2011). Social-emotional and physical development, by means of sports, nutrition and mindfulness are important elements to create a healthy and stimulating breeding ground to learn to deal with all sorts of daily life events.

\section{Acknowledgements}

This research was facilitated by mental healthcare cooperation UVIT/VGZ. We would like to thank the children and parents whose participation made the study possible. We also thank BeterBrein (B. Gerrits, M. Gerrits, W. van der Zwaag) for selecting and coaching the Cogmed@ coaches and for providing us with the data.

\section{References}

Alexander, A. W., \& Slinger-Constant, A. M. (2004). Current Status of Treatment for Dyslexia: Critical Review. Journal of Child Neurology, 19, 744-758.

Alloway, T. P., \& Alloway, R. G. (2010). Investigating the Predictive Roles of Working Memory and IQ in Academic Attainment. Journal of Experimental Child Psychology, 106, 20-29. http://dx.doi.org/10.1016/j.jecp.2009.11.003

American Psychiatric Association (2000). Diagnostic and Statistical Manual of Mental Disorders (4th ed.). Revised. Washington DC: American Psychiatric Association Press.

American Psychiatric Association (2013). Diagnostic and Statistical Manual of Mental Disorders (5th ed.). Washington DC: American Psychiatric Association Press.

Arnsten, A. F., \& Rubia, K. (2012). Neurobiological Circuits Regulating Attention, Cognitive Control, Motivation, and Emotion: Disruptions in Neurodevelopmental Psychiatric Disorders. Journal of the American Academy of Child \& Adolescent Psychiatry, 51, 356-367. http://dx.doi.org/10.1016/j.jaac.2012.01.008

Aronen, E. T., Vuontela, V., Steenari, M. R., Salmi, J., \& Carlson, S. (2005). Working Memory, Psychiatric Symptoms, and Academic Performance at School. Neurobiological of Learning and Memory, 83, 33-42.

http://dx.doi.org/10.1016/j.nlm.2004.06.010

Atkinson, M., \& Hollis, C. (2010). NICE Guideline: Attention Deficit Hyperactivity Disorder. Archives of Disease in Childhood. Education and Practice Edition, 95, 24-27. http://dx.doi.org/10.1136/adc.2009.175943

Baddeley, A. (1992). Working Memory. Science, 255, 556-559. http://dx.doi.org/10.1126/science.1736359

Barbey, A. K., Koenigs, M., \& Grafman, J. (2013). Dorsolateral Prefrontal Contributions to Human Working Memory. Cortex, 49, 1195-1205. http://dx.doi.org/10.1016/j.cortex.2012.05.022

Barkley, R. A. (1997). Behavioral Inhibition, Sustained Attention, and Executive Functions: Constructing a Unifying Theory of ADHD. Psychological Bulletin, 121, 65-94. http://dx.doi.org/10.1037/0033-2909.121.1.65 
Bigorra, A., Garolera, M., Guijarro, S., \& Hervas, A. (2015). Long-Term Far-Transfer Effects of Working Memory Training in Children with ADHD: A Randomized Controlled Trial. European Child and Adolescent Psychiatry, 1-15. http://dx.doi.org/10.1007/s00787-015-0804-3

Butterworth, B. (2010). Foundational Numerical Capacities and the Origins of Dyscalculia. Trends in Cognitive Sciences, 14, 534-541. http://dx.doi.org/10.1016/j.tics.2010.09.007

Cain, K., Oakhill, J., \& Bryant, P. (2004). Children’s Reading Comprehension Ability: Concurrent Prediction by Working Memory, Verbal Ability and Component Skills. Journal of Educational Psychology, 96, 31-42. http://dx.doi.org/10.1037/0022-0663.96.1.31

Caspi, O., \& Bootzin, R. R. (2002). Evaluating How Placebos Procedure Change: Logical and Casual Traps and Understanding Cognitive Explanatory Mechanisms. Evaluation \& the Health Professions, 25, 436-464. http://dx.doi.org/10.1177/0163278702238056

Chacko, A., Feirsen, N., Bedard, A. C., Marks, D., Uderman, J. Z., \& Chimiklis, A. (2013). Cogmed Working Memory Training for Youth with ADHD: A Closer Examination of Efficacy Utilizing Evidence-Based Criteria. Journal of Clinical Child \& Adolescent Psychology, 42, 769-783. http://dx.doi.org/10.1080/15374416.2013.787622

Cortese, S., Ferrin, M., Brandeis, D., Buitelaar, J., Daley, D., Dittmann, R.W. et al., on Behalf of the European ADHD Guidelines Group (2015). Cognitive Training for Attention-Deficit/Hyperactivity Disorder: Meta-Analysis of Clinical and Neuropsychological Outcomes from randomized Controlled Trials. Journal of the American Academy of Child \& Adolescent Psychiatry, 54, 164-174. http://dx.doi.org/10.1016/j.jaac.2014.12.010

Dahlin, K. I. E. (2011). Effects of Working Memory Training on Reading in Children with special Needs. Reading and Writing, 24, 479-491. http://dx.doi.org/10.1007/s11145-010-9238-y

Denckla, M. B. (1996). Biological Correlates of Learning and Attention: What Is Relevant to Learning Disability and Attention-Deficit Hyperactivity Disorder? Developmental and Behavioral Pediatrics, 17, 114-119. http://dx.doi.org/10.1097/00004703-199604000-00011

Friso-van den Bos, I., Van der Ven, S. H. G., Kroesbergen, E. H., \& Van Luit, J. E. H. (2013). Working Memory and Mathematics in Primary School Children: A Meta-Analysis. Educational Research Review, 10, 29-44. http://dx.doi.org/10.1016/j.edurev.2013.05.003

Gathercole, S. E., \& Alloway, T. P. (2006). Practitioner Review: Short-Term and Working Memory Impairments in Neurodevelopmental Disorders: Diagnosis and Remedial Support. Journal of Child Psychology and Psychiatry, 47, 4-15. http://dx.doi.org/10.1111/j.1469-7610.2005.01446.x

Gathercole, S. E., \& Pickering, S. J. (2000). Working Memory Deficits in Children with Low Achievements in the National Curriculum at 7 Years of Age. British Journal of Educational Psychology, 70, 177-194. http://dx.doi.org/10.1348/000709900158047

Gathercole, S. E., Tiffany, C., Briscoe, J., Thorn, A., \& The ALSPAC Team (2005). Developmental Consequences of Poor Phonological Short-Term Memory Function in Childhood: A Longitudinal Study. Journal of Child Psychology and Psychiatry, 46, 598-611. http://dx.doi.org/10.1111/j.1469-7610.2004.00379.x

Gioia, G. A., Isquith, P. K., Guy, S. C., \& Kenworthy, L. (2000). Behavior Rating Inventory of Executive Function. Child Neuropsychology, 6, 235-238. http://dx.doi.org/10.1076/chin.6.3.235.3152

Gray, S. A., Chaban, R., Martinussen, R., Goldberg, H., Gotlieb, R., Kronitz, R, Hockenberry, M., \& Tannock, R. (2012). Effects of a Computerized Working Memory Program on Working Memory, Attention, and Academics in Adolescents with Severe LD and Comorbid ADHD: A Randomized Clinical Trial. Journal of Child Psychology and Psychiatry, 53, 1277-1284. http://dx.doi.org/10.1111/j.1469-7610.2012.02592.x

Hale, J., Alfonso, V., Berninger, V., Bracken, B., Christo, C., Clark, E. et al. (2010). Critical Issues in Response-to-Intervention, Comprehensive Evaluation, and Specific Learning Disabilities Identification and Intervention: An Expert White Paper Consensus. Learning Disability Quarterly, 33, 223-236. http://dx.doi.org/10.1177/073194871003300310

Hodgson, K., Hutchinson, A. D., \& Denson, L. (2012). Nonpharmacological Treatments for ADHD. A Meta-Analytic Review. Journal of Attention Disorders, 18, 275-282. http://dx.doi.org/10.1177/1087054712444732

Holmes, J., Gathercole, S. E., \& Dunning, D. L. (2009). Adaptive Training Leads to Sustained Enhancement of Poor Working Memory in Children. Developmental Science, 12, F9-F15. http://dx.doi.org/10.1111/j.1467-7687.2009.00848.x

Hovik, K. T., Saunes, B.-K., Aarlien, A. K., \& Egeland, J. (2013). RCT of Working Memory Training in ADHD: Long-Term Near-Transfer Effects. PLoS ONE, 8, e80561. http://dx.doi.org/10.1371/journal.pone.0080561

Jeffries, S., \& Everatt, J. (2004). Working Memory: Its Role in Dyslexia and Other Specific Learning Disorders. Dyslexia, 10, 196-214. http://dx.doi.org/10.1002/dys.278

Jerman, O., Reynolds, C., \& Swanson, H. L. (2012). Does Growth in Working Memory Span or Executive Processes Predict Growth in Reading and Math in Children with Reading Disabilities? Learning Disability Quarterly, 3, 144-157.

Kasper, L. J., Matt Alderson, R., \& Hudec, K. L. (2012). Moderators of Working Memory Deficits in Children with Atten- 
tion-Deficit/Hyperactivity Disorder (ADHD): A Meta-Analytic Review. Clinical Psychological Review, 32, 605-617. http://dx.doi.org/10.1016/j.cpr.2012.07.001

Kenworthy, L., Yerys, B. E., Anthony, L. G., \& Wallace, G. L. (2008). Understanding Executive Control in Autism Spectrum Disorders in the Lab and in the Real World. Neuropsychology Review, 18, 320-338.

http://dx.doi.org/10.1007/s11065-008-9077-7

Klingberg, T. (2010). Training and Plasticity of Working Memory. Trends in Cognitive Sciences, 14, 317-324. http://dx.doi.org/10.1016/j.tics.2010.05.002

Klingberg, T., Fernell, E., Olesen, P. J., Johnson, M., Gustafsson, P., Dahlstrom, K. et al. (2005). Computerized Training of Working Memory in Children with ADHD-A Randomized Controlled Trial. Journal of the American Academy of Child and Adolescent Psychiatry, 44, 177-186. http://dx.doi.org/10.1097/00004583-200502000-00010

Klingberg, T., Forssberg, H., \& Westerberg, H. (2002). Training of Working Memory in Children with ADHD. Journal of Clinical and Experimental Neuropsychology, 2, 781-791. http://dx.doi.org/10.1076/jcen.24.6.781.8395

Landerl, K., Fussenegger, B., Moll, K., \& Willburger, E. (2009). Dyslexia and Dyscalculia: Two Learning Disorders with Different Cognitive Profiles. Journal of Experimental Psychology, 103, 309-324.

http://dx.doi.org/10.1016/i.jecp.2009.03.006

Lazar, J. W., \& Frank, Y. (1998). Frontal Systems Dysfunction in Children with Attention-Deficit/Hyperactivity Disorder and Learning Disabilities. Journal of Neuropsychiatry and Clinical Neurosciences, 10, 160-167. http://dx.doi.org/10.1176/jnp.10.2.160

Loosli, S. V., Buschkuehl, M., Perrig, W. J., \& Jaeggi, S. M. (2012). Working Memory Training Improves Reading Processes in Typically Developing Children. Child Neuropsychology, 18, 62-78.

http://dx.doi.org/10.1080/09297049.2011.575772

Lyon, G. R. (1996). Learning Problems for Disabilities. Future Child, 6, 54-76. http://dx.doi.org/10.2307/1602494

Martinussen, R., \& Tannock, R. (2006). Working Memory Impairments in Children with Attention-Deficit Hyperactivity Disorder with and without Comorbid Language Learning Disorders. Journal of Clinical and Experimental Neuropsychology, 28, 1073-1094. http://dx.doi.org/10.1080/13803390500205700

Martinussen, R., Hayden, J., Hogg-Johnson, S., \& Tannock, R. (2005). A Meta-Analysis of Working Memory Impairments in Children with Attention-Deficit/Hyperactivity Disorder. Journal of the American Academy of Child and Adolescent Psychiatry, 44, 377-384. http://dx.doi.org/10.1097/01.chi.0000153228.72591.73

Mazzocco, M. M., \& Kover, S. T. (2007). A Longitudinal Assessment of Executive Function Skills and Their Association with Math Performance. Child Neuropsychology, 13, 18-45. http://dx.doi.org/10.1080/09297040600611346

McNab, F., Varrone, A., Farde, L., Jucaite, A., Bystritsky, P., Forssberg, H., \& Klingberg, T. (2009). Changes in Cortical Dopamine D1 Receptor Binding Associated with Cognitive Training. Science, 323, 800-802. http://dx.doi.org/10.1126/science.1166102

McNamara, J., Vervaeke, S. L., \& Willoughby, T. (2008). Learning Disabilities and Risk-Taking Behaviour in Adolescents. Journal of Learning Disabilities, 41, 561-574. http://dx.doi.org/10.1177/0022219408326096

Melby-Lervag, M., \& Hulme, C. (2012). Is Working Memory Training Effective? A Meta-Analytic Review. Developmental Psychology, 49, 270-291.

MTA Cooperative Group (2004). National Institute of Mental Health Multimodal Treatment Study of ADHD Follow-Up: Changes in Effectiveness and Growth after the End of Treatment. Pediatrics, 113, 762-769. http://dx.doi.org/10.1542/peds.113.4.762

Novik, T. S., Hervas, A., Ralston, S. J., Dalsgaard, S., Rodriques, P. R., \& Lorenzo, M. J. (2006). Influence of Gender on Attention-Deficit/Hyperactivity Disorder in Europe-ADORE. European Child and Adolescent Psychiatry, 15, 115-124. http://dx.doi.org/10.1007/s00787-006-1003-z

Ostberg, M., \& Rydell, A. M. (2012). An Efficacy Study of a Combined Parent and Teacher Management Training Programme for Children with ADHD. Nordic Journal of Psychiatry, 66, 123-130. http://dx.doi.org/10.3109/08039488.2011.641587

Passolunghi, M. C., \& Mammarella, I. C. (2012). Selective Spatial Working Memory Impairment in a Group of Children with Mathematics Learning Disabilities and Poor Problem-Solving Skills. Journal of Learning Disabilities, 45, 341-350. http://dx.doi.org/10.1177/0022219411400746

Polanczyk, G., de Lima M. S., Horta, B. L., Biederman, J., \& Rohde, L. A. (2007). The Worldwide Prevalence of ADHD: A Systematic Review and Metaregression Analysis. American Journal of Psychiatry, 164, 942-948.

http://dx.doi.org/10.1176/ajp.2007.164.6.942

Rapport, M. D., Chung, K., Shore, G., \& Isaacs, P. (2001). A Conceptual Model of Child Psychopathology: Implications for Understanding Attention Deficit Hyperactivity Disorder and Treatment Efficacy. Journal of Clinical Child Psychology, 30, 
48-58. http://dx.doi.org/10.1207/S15374424JCCP3001_6

Rapport, M. D., Orban, S. A., Kofler, M. J., \& Friedman, L. M. (2013). Do Programs Designed to Train Working Memory, Other Executive Functions, and Attention Benefit Children with ADHD? A Meta-Analytic Review of Cognitive, Academic, and Behavioural Outcomes. Clinical Psychological Review, 33, 1237-1252.

http://dx.doi.org/10.1016/j.cpr.2013.08.005

Rogers, M., Hwang, H., Toplak, M., Weiss, M., \& Tannock, R. (2011). Inattention, Working Memory, and Academic Achievement in Adolescents Referred for Attention Deficit/Hyperactivity Disorder (ADHD). Child Neuropsychology, 17, 444-458. http://dx.doi.org/10.1080/09297049.2010.544648

Scholte, E. M., \& Van der Ploeg, J. D. (2005). Handleiding ADHD-Vragenlijst (AVL). Houten: Bohn Stafleu van Loghum Publishers.

Schulte-Korne, G. (2010). The Prevention, Diagnosis, and Treatment of Dyslexia. Deutsches Ärzteblatt International, 107, 718-726.

Semrud-Clikeman, M. (2005). Neuropsychological Aspects for Evaluating Learning Problems. Journal of Learning Disabilities, 38, 563-568. http://dx.doi.org/10.1177/00222194050380061301

Sexton, C. C., Gelhorn, H. L., Bell, J. A., \& Classi, P. M. (2012). The Co-Occurrence of Reading Disorder and ADHD: Epidemiology, Treatment, Psychosocial Impact and Economic Burden. Journal of Learning Disabilities, 45, 538-564. http://dx.doi.org/10.1177/0022219411407772

Shalev, R. S. (2000). Developmental Dyscalculia: Prevalence and Prognosis. European Child and Adolescent Psychiatry, 9 , 58-64. http://dx.doi.org/10.1007/s007870070009

Shinaver, C. S., Entwistle, P. C., \& Söderqvist, S. (2014). Cogmed WM Training: Reviewing the Reviews. Applied Neuropsychology: Child, 3, 163-172. http://dx.doi.org/10.1080/21622965.2013.875314

Shipstead, Z., Redick, T. S., \& Engle, R. W. (2012). Is Working Memory Training Effective? Psychological Bulletin, 138, 628-654. http://dx.doi.org/10.1037/a0027473

Smidts, D., \& Huizinga, M. (2009). Executieve Functies Vragenlijst (BRIEF). Amsterdam: Hogrefe Publishers.

Snowling, M. J., \& Hulme, C. (2012). Interventions for Children’s Language and Literacy Difficulties. International Journal of Language and Communication Disorders, 47, 27-34. http://dx.doi.org/10.1111/j.1460-6984.2011.00081.x

Sonuga-Barke, E. J. S, Brandeis, D., Cortese, S., Daley, D., Ferrin, M., Holtmann, M. et al. (2013). Nonpharmacological Interventions for ADHD: Systematic Review and Meta-Analyses of Randomized Controlled Trials of Dietary and Psychological Treatments. American Journal of Psychiatry, 170, 275-289. http://dx.doi.org/10.1176/appi.ajp.2012.12070991

Strand, M. T., Hawk, L. W., Bubnik, M., Shiels, K., Pelham, W. E., \& Waxmonsky, J. G. (2012). Improving Working Memory in Children with Attention-Deficit/Hyperactivity Disorder: The Separate and Combined Effects of Incentives and Stimulant Medication. Journal of Abnormal Child Psychology, 40, 1193-1207. http://dx.doi.org/10.1007/s10802-012-9627-6

Swanson, H. L., \& Beebe-Frankenberger, M. (2004). The Relationship between Working Memory and Mathematical Problem Solving in Children at Risk for Math Disabilities. Journal of Education Psychology, 96, 471-491. http://dx.doi.org/10.1037/0022-0663.96.3.471

Swanson, H. L., Zheng, X., \& Jerman, O. (2009). Working Memory, Short-Term Memory and Reading Disabilities. A Selective Meta-Analysis of the Literature. Journal of Learning Disabilities, 42, 260-287. http://dx.doi.org/10.1177/0022219409331958

Swanson, J. M., \& Volkow, N. D. (2009). Psychopharmacology: Concepts and Opinions about the Use of Stimulant Medications. Journal of Child Psychology and Psychiatry, 50, 180-193. http://dx.doi.org/10.1111/j.1469-7610.2008.02062.x

Tannock, R., \& Brown, T. E. (2000). Attention-Deficit Disorders and Comorbidities in Children, Adolescents and Adults. Washington DC: American Psychiatric Press.

Toll, S. W. M., Van der Ven, S. H. G., Kroesbergen, E. H., \& Van Luit, J. E. H. (2011). Executive Functions as Predictors of Math Learning Disabilities. Journal of Learning Disabilities, 44, 521-532. http://dx.doi.org/10.1177/0022219410387302

Trimbos-Instituut (2005). Multidisciplinaire Richtlijn voor diagnostiek en behandeling van ADHD bij kinderen en jeugdigen. Utrecht: Trimbos-instituut.

Unsworth, N., \& Engle, R. W. (2007). On the Division of Short-Term and Working Memory: An Examination of Simple and Complex Span and Their Relation to Higher Order Abilities. Psychological Bulletin, 6, 1038-1066. http://dx.doi.org/10.1037/0033-2909.133.6.1038

Van der Loo-Neus, G. H., Rommelse, N., \& Buitelaar, J. K. (2011). To Stop or Not to Stop? How Long Should Medication Treatment of Attention-Deficit Hyperactivity Disorder Be Extended? European Neuropsychopharmacology, 21, $584-599$. http://dx.doi.org/10.1016/j.euroneuro.2011.03.008

Verhulst, F. C., Van der Ende, J., \& Koot, H. M. (1996). Handleiding van de CBCL/4-18. Rotterdam: Afdeling Kinder-en 
Jeugdpsychiatrie, Sophia Kinderziekenhuis/Academisch Ziekenhuis Rotterdam, Erasmus Universiteit.

Willcutt, E. G., Betjemann, R. S., McGrath, L. M., Chhabildas, N. A., Olson, R. K., DeFries, J. C., \& Pennington, B. F. (2010). Etiology and Neuropsychology of Comorbidity between RD and ADHD: The Case for Multiple-Deficit Models. Cortex: A Journal Devoted to the Study of the Nervous System and Behavior, 46, 1345-1361.

http://dx.doi.org/10.1016/j.cortex.2010.06.009

Willcutt, E. G., Doyle, A. E., Nigg, J. T., Faraone, S. V., \& Pennington, B. F. (2005). Validity of Executive Function Theory of Attention-Deficit/Hyperactivity Disorder: A Meta-Analytic Review. Biologic Psychiatry, 57, 1336-1346.

http://dx.doi.org/10.1016/j.biopsych.2005.02.006 